\title{
Modelagem matemática para o estudo de função afim: uma possibilidade de aprendizagem a partir da conta de água
}

\author{
Cássia Silva Costa (iD) \\ Secretaria de Estado da Educação \\ de Minas Gerais
}

曰 cassia.silva.costa@hotmail.com

Rogério Fernando Pires (D)

Universidade Federal de

Uberlândia/PPGECE-UFSCar

》rfpires25@hotmail.com

Carlos Eduardo Petronilho Boiago

Secretaria de Estado da Educação de Minas Gerais

פcadu matematica@hotmail.com

\author{
Mathematical modeling for the study of affine function: a \\ possibility of learning from the water bill
}

\begin{abstract}
The present work aims to present the results of a research carried out with 1st year high school students from a public school in the city of Ituiutaba - MG, which sought to investigate the potential and limitations of a teaching intervention based on the account analysis of water from these students, following the assumptions of Mathematical Modeling and Theory of Semiotic Representation Records. The qualitative and quantitative study included the participation of 30 students who, during sixteen meetings, carried out activities that made it possible to model water consumption in homes in the municipality of Ituiutaba. The proposed tasks were based on the possibility of using cognitive activities of conversion and treatment, related to Raymond Duval's theory. Given the records presented, it was evident that in activities with treatment of numerical records, students performed better than using the conversion of records. It was also diagnosed that the transition from the algebraic register to the graphic register of the mathematical object (affine function), presents a difficulty for students. In another perspective, students began to have a critical attitude based on the results found, to the point of discovering that different rates are charged in the municipality depending on the neighborhood, and that, for the first range of consumption, the individual who obtained a lower real consumption, pays the same amount as the one who consumed more.
\end{abstract}

Key words: Mathematical Modeling; Affine Function; Theory of Semiotic Representation Records.

\begin{abstract}
Resumo
O presente trabalho tem por objetivo expor os resultados de uma pesquisa realizada com alunos do $1 .^{\circ}$ ano do Ensino Médio de uma escola pública do município de Ituiutaba MG, que buscou investigar as potencialidades e as limitações de uma intervenção de ensino a partir da análise da conta de água desses estudantes, seguindo os pressupostos da Modelagem Matemática e da Teoria dos Registros de Representação Semiótica. 0 estudo de cunho qualitativo e quantitativo contou com a participação de 30 alunos que, durante dezesseis encontros, realizaram atividades que possibilitaram modelar o consumo d'água nas residências no município de Ituiutaba. As tarefas propostas pautaramse pela possibilidade do uso das atividades cognitivas de conversão e tratamento, referentes à teoria de Raymond Duval. Diante dos registros obtidos foi evidenciado que, em atividades com tratamentos de registros numéricos, os alunos demonstraram meIhor desempenho do que usando a conversão de registros. Diagnosticou-se, ainda, que a transição do registro algébrico para o registro gráfico do objeto matemático (função afim) apresenta uma dificuldade para os alunos. Em outra perspectiva, os estudantes passaram a ter uma atitude crítica diante dos resultados encontrados, a ponto de descobrirem que no município são cobradas tarifas diferentes dependendo do bairro e que, para a primeira faixa de consumo, o indivíduo que atingiu um menor consumo real paga a mesma quantia daquele que consumiu mais.

Palavras-chave: Modelagem Matemática; Função Afim; Teoria de Registros de Representação Semiótica.
\end{abstract}




\section{INTRODUÇÃO}

Um dos objetivos para o ensino da Matemática na escola básica, de acordo com os Parâmetros Curriculares Nacionais [16], é saber selecionar, organizar e produzir informações relevantes para interpretá-las e avaliá-las criticamente. Nem sempre as aulas propiciam condições para que os próprios alunos busquem tais informações para, a partir delas, construir novos conhecimentos. Além disso, comunicar-se matematicamente e estabelecer conexões com temas matemáticos de diferentes campos e entre esses temas e conhecimentos de outras áreas curriculares são competências pouco desenvolvidas nessa área.

Por essa razão, o ensino da Matemática não pode ficar atrelado à simples memorização de técnicas, visto que a Matemática se constitui como um conhecimento produzido pelo homem, desenvolvedor de seu raciocínio lógico, estimulando o pensamento independente, a criatividade e a capacidade de resolver problemas. A atividade matemática é um desafio importante em nossa sociedade, e, para que isso se torne possível, é necessária uma postura de ensino apropriada e significativa, relacionando o papel do professor e as práticas adequadas para a aprendizagem e ensino de Matemática.

Um dos recursos que o professor pode utilizar em suas aulas é a Modelagem Matemática, uma vez que ela proporciona atividades investigadoras, interativas e dinâmicas, levando os alunos a relacionarem o que estudam na escola com a realidade em diversas áreas do conhecimento e compreender melhor os conceitos matemáticos em sua prática social.

Bassanezi afirma que a "Modelagem Matemática utilizada como estratégia de ensinoaprendizagem é um dos caminhos a ser seguido para tornar um curso de Matemática, em qualquer nível, mais atraente e agradável" [2] (p. 177).

A motivação para a realização desta pesquisa surgiu a partir de estudos efetuados pela primeira autora no âmbito de um programa de bolsas de iniciação científica da Universidade Federal de Uberlândia fomentado pelo CNPQ, relacionados à utilização da modelagem matemática como metodologia de ensino na Educação Básica, como também à Educação Matemática Crítica e à Teoria dos Registros de Representação Semiótica, os quais faziam parte de um projeto de pesquisa coordenado pelo segundo autor deste artigo.

A partir de tais estudos, surgiu o seguinte questionamento, o qual norteou a presente pesquisa: Quais as potencialidades e limitações de uma sequência de atividades sobre função afim para alunos do $1 .^{\circ}$ ano do Ensino Médio pautada pelos pressupostos da Modelagem Matemática à luz da Teoria dos Registros de Representação Semiótica? 
Considerando essa questão, ressaltamos que o objetivo principal desta pesquisa foi analisar as potencialidades e limitações de uma sequência de atividades sobre função afim para alunos do $1 .^{\circ}$ ano do Ensino Médio pautada pelos pressupostos da Modelagem Matemática à luz da Teoria dos Registros de Representação Semiótica.

\section{MODELAGEM MATEMÁTICA}

A modelagem matemática não é uma ideia recente. Ela sempre esteve presente na criação das teorias científicas e, em especial, das teorias matemáticas [6] (p. 15).

A ideia de abordagem da Modelagem Matemática parte de um tema real do cotidiano, baseado na experiência dos alunos sobre determinado assunto e, a partir dessas experiências, mostram-se aplicações práticas de algum conteúdo da Matemática, com a finalidade de facilitar o entendimento dos alunos sobre tal temática.

Atualmente, diversos pesquisadores da área têm discutido bastante sobre a Modelagem Matemática para o ensino da Matemática, entre eles, podem-se citar [2] e [5], todos com ideias de relacionar conteúdos escolares com um problema do contexto do aluno. Mas o que é Modelagem Matemática? Algumas investigações indicam que há várias áreas de pesquisas sobre o assunto. Muitos autores, entretanto, caracterizam a Modelagem Matemática como um processo usado para obter e regularizar modelos matemáticos a partir da realidade e do contexto do aluno.

Segundo [2], a modelagem consiste na arte de transformar situações da realidade em problemas matemáticos cujas soluções devem ser interpretadas na linguagem usual. Conforme o autor, a Modelagem Matemática só funciona a partir do momento que todos envolvidos se conscientizam de que ela e a realidade estão associadas, e, ademais, deve ter uma sequência em que haja experimentação, abstração, resolução, validação e aplicação dessa metodologia.

Segundo [5], podemos dizer que, genericamente, Matemática e realidade são dois conjuntos separados e a Modelagem é um meio de fazê-los interagir.

Portanto, podemos fazer da Matemática algo mais interessante a partir do momento que os alunos a enxergam em sua vida, na sala de aula, no trabalho, em seus passeios, enfim, em seu cotidiano. A Modelagem é uma ferramenta que tem o domínio de unir a Matemática e a realidade, de forma que ela abranja todas as disciplinas e conteúdos de maneira interdisciplinar e contextualizada.

Para [5] (p. 13), a Modelagem Matemática pode ser vista como "formular, resolver e elaborar expressões que valham não apenas para uma solução particular, mas que também sirvam, posteriormente, como suporte para outras aplicações e teorias".

Quando o professor usa um conjunto de símbolos e relações matemáticas a fim de traduzir um fenômeno ou problema real, este utiliza então um modelo matemático [5], 
capaz de "despertar no aluno o interesse por tópicos matemáticos que ainda desconhece ao mesmo tempo em que aprende a arte de modelar, matematicamente" [4] (p. 36).

Ainda na perspectiva de [5], esse processo de Modelagem como processo matemático é dividido em três etapas, quais sejam:

a) Interação: é o reconhecimento da situação-problema e a familiarização com o assunto a ser modelado. A situação-problema torna-se cada vez mais clara à medida que se vai interagindo com os dados.

b) Matematização: seu objetivo principal é chegar a um conjunto de expressões aritméticas ou fórmulas, ou equações algébricas ou gráficas, ou representações, ou programa computacional, que levem à solução ou permitam a dedução de uma solução.

c) Modelo Matemático: essa etapa consiste em verificar, interpretar e validar se o modelo matemático obtido soluciona a situação-problema estudada. É interpretação do modelo, verificação e sua validação. Se o modelo não for viável, [5] (p. 15) sugere que "o processo deve ser retomado na segunda etapa - matematização -, mudando-se ou ajustando hipóteses, variáveis etc.".

No entender de [15], o modelo é uma imagem que se forma na mente, no momento em que o espírito racional busca compreender e expressar de forma intuitiva uma sensação, procurando relacioná-la com algo já conhecido, efetuando deduções.

De acordo com [2], o modelo matemático é considerado um conjunto de símbolos e relações matemáticas que representam, de alguma forma, o objeto estudado. Um modelo pode ser formulado em âmbito familiar, utilizando-se de expressões numéricas ou fórmulas, diagramas, gráficos ou representações geométricas, equações algébricas, tabelas, programas computacionais etc.

O processo de Modelagem consiste em interpretar matematicamente situações oriundas do mundo real em que as pessoas vivem. Assim, esse processo pode ter seu início a partir dos dados encontrados em contas de energia, água, telefone etc., cujas informações podem ser interpretadas por modelos dinâmicos relacionados às funções e modelos estáticos, como aqueles da Geometria Plana e Espacial. Para a criação de modelos é preciso partir de um fato realístico ou objeto e realizar uma coleta de dados, fazer reconhecimento do papel da Matemática na sociedade, aquisição de conceitos matemáticos e suas aplicações, desenvolvimento do conhecimento reflexivo e os processos cognitivos desenvolvidos pelos alunos. 
"Modelagem, na perspectiva da Educação Matemática, é um ambiente de aprendizagem no qual os alunos são convidados a problematizar e investigar, por meio da Matemática, situações com referência na realidade." [1]

Ao observar toda a discussão acerca do ensino por meio da modelagem, surge um questionamento: Por que utilizar Modelagem Matemática como metodologia de ensino? Muitas vezes os alunos questionam o professor por que devem estudar determinados conteúdos de Matemática, para que servem e se algum dia eles serão úteis.

Nas aulas de Matemática, o professor tem se valido de situações desconectadas da realidade do aluno, as quais não fazem sentido em suas vidas, o que certamente poderá prejudicar o desenvolvimento da aprendizagem.

Para que o professor possa adotar a Modelagem Matemática como método de ensino em suas aulas, ele precisa ter um bom conhecimento dela, sobre o conteúdo de Matemática e ter noções de outras áreas de conhecimento. De maneira simples, a Modelagem Matemática pode ser entendida como o uso da Matemática para estudar problemas reais.

De acordo com [10], a Modelagem Matemática é uma forma de interação do conteúdo específico da sala de aula com situações reais. Para o autor, a Modelagem é um processo muito rico para abordar questões reais, resultando uma solução efetiva do problema e que certamente não é uma simples resolução de um problema matemático artificial.

Portanto, a Modelagem Matemática no ensino pode ser um caminho para despertar no aluno o interesse por tópicos matemáticos que ele ainda desconhece e ao mesmo tempo aprende a arte de modelar, matematicamente.

Segundo [6], a Modelagem Matemática é uma metodologia de ensino que se constitui em um conjunto de procedimentos, cujo objetivo é construir um paralelo para tentar explicar, matematicamente, os fenômenos presentes no cotidiano do ser humano, ajudando-o a fazer predições e a tomar decisões. O autor [2] (p. 38) ilustra esse posicionamento ao comentar que:

A modelagem no ensino é apenas uma estratégia de aprendizagem, onde o mais importante não é chegar imediatamente a um modelo bem-sucedido, mas caminhar seguindo etapas onde o conteúdo matemático vai sendo sistematizado e aplicado. Com a modelagem o processo de ensino-aprendizagem não mais se dá no sentido único do professor para o aluno, mas como resultado da interação do aluno com seu ambiente natural.

A modelagem sugere que, a partir de situações reais, o aluno tenha condições de resolver e solucionar problemas. Por meio dela, os alunos problematizam e investigam 
essas situações. No entanto, em sala de aula, o professor deve respeitar o programa e os planejamentos, não ficando estritamente ligado à Modelagem por si só. Quando o professor se interessa pelo processo de Modelagem, decide aplicá-lo e ainda assim se preocupa em atender ao seu cronograma, então ocorre a chamada modelação matemática. Segundo [5], o professor pode escolher determinados modelos e recriá-los em sala de aula com os alunos, de acordo com o nível em questão, além de obedecer ao currículo inicialmente proposto.

Modelação Matemática é o método que, alienado da Modelagem, desenvolve os conteúdos matemáticos em ensino regular, assim como no ensino médio, por meio da análise e da criação de modelos, admitindo a possibilidade de estabelecer uma relação da Matemática com outras áreas do conhecimento humano, bem como a Matemática com ela própria, o que pode ser apresentado como aplicação da prática cotidiana, despertando o interesse do aluno.

Esse processo contribuiu de forma decisiva para a compreensão dos conceitos matemáticos, para estimular a criatividade e, também, desenvolver habilidades para resolver problemas.

\section{A TEORIA DOS REGISTROS DE REPRESENTAÇÃO SEMIÓTICA}

Visando contribuir para o entendimento da apreensão dos objetos matemáticos presentes nas atividades de Modelagem Matemática, foi utilizada a Teoria dos Registros de Representação Semiótica de Raymond Duval.

Essa teoria, proposta pelo filósofo e psicólogo Raymond Duval, foi criada com o objetivo de estudar e analisar como funciona o pensamento para a obtenção do conhecimento pelo aluno, por meio de representações, e a forma que processa a aprendizagem. Para o autor, a utilização de diferentes registros de representação associados a um mesmo objeto matemático, o tratamento, a conversão e a coordenação adequada entre esses registros possibilitam ao aluno compreender o objeto matemático como um todo.

A Teoria dos Registros de Representação Semiótica busca examinar a influência das representações dos objetos matemáticos no processo de ensino e aprendizagem em Matemática. Segundo o autor, esses registros semióticos são "produções constituídas pelo emprego de signos pertencentes a um sistema de representações que tem inconvenientes próprios de significação e de funcionamento" [12] (p. 269).

Para [12], as representações não são somente necessárias para fins de comunicação, elas são igualmente essenciais à atividade cognitiva do pensamento. Assim, fica evidente a importância do uso das representações semióticas no processo de estudo dos objetos matemáticos. É por meio dos registros de representação que são defini- 
dos os diversos tratamentos utilizados no estudo dos objetos matemáticos, realçando a importância dos registros para construção do conhecimento.

O tratamento de um registro de representação consiste em transformar a representação do objeto matemático mantendo o próprio registro em que se desenvolveu.

\begin{abstract}
Os tratamentos são transformações de representações dentro de um mesmo registro: por exemplo, efetuar um cálculo ficando estritamente no mesmo sistema de escrita ou de representação dos números; resolver uma equação ou sistema de equações; completar uma figura segundo critérios de conexão e simetria [9] (p. 160).
\end{abstract}

Assim, se o conceito de um determinado assunto, por exemplo, "porcentagem", o professor utilizar somente o método da regra de três como resolução, na medida em que os alunos realizarem os cálculos, compreenderão como se faz para calcular o resultado de uma aplicação de porcentagem, realizando apenas tratamentos em um só tipo de representação. Isso não significa que o aluno assimilou o conceito, mas mostra que ele sabe manipular uma das representações desse objeto matemático.

Portanto, é preciso adequar uma abordagem que relacione vários registros para a compreensão de um conceito matemático. Nesse sentido, [12] sugere que a conversão entre os registros de representação semiótica seja explorada.

Segundo [12], a conversão é a transformação de uma representação de um objeto matemático interpretado em outra representação. O autor estabelece três tipos de conversão para os registros: a ilustração (é a conversão de uma representação linguística em uma representação figural); a tradução (é a conversão de uma representação linguística numa língua dada, em outra representação linguística de outro tipo de língua); e a descrição (é a conversão de uma representação não verbal).

No entanto, ao realizarem a atividade de conversão, é preciso que os alunos saibam diferenciar a representação do conceito matemático representado.

Logo, conforme o autor, a análise dos tratamentos é totalmente distinta das conversões, pois acomete a dois diferentes domínios cognitivos, ou seja, os tratamentos são tarefas de produções, internos a um determinado conteúdo, e as conversões, por sua vez, são tarefas de compreensão que ocorrem entre os registros.

Em sua obra, [10] diz que, quando acontece a transformação de um registro para outro, a atividade de conversão apresenta fenômenos característicos que envolvem os conceitos de congruência e de não congruência e a importância do sentido da conversão.

O autor ainda menciona a relevância de estabelecer a diferença entre esses fenômenos e analisar a atividade de conversão para comparar as representações no re- 
gistro de partida com o registro de chegada.

Esquematicamente duas situações podem ocorrer. Ou a representação terminal transparece na representação de saída e a conversão está próxima de uma situação de simples codificação - diz então que há congruência -, ou ela não transparece absolutamente e se dirá que ocorre a não congruência. Existem na verdade muitos fatores que estabelecem o caráter de congruência e não congruência de uma conversão [...] [9] (p. 19).

Assim, o autor considera que a atividade de conversão não é algo estritamente conceitual, visto que, envolve o conceito de congruência e não congruência. Uma conversão é considerada congruente quando ocorre a passagem natural de um registro de representação de partida para outro registro de representação de chegada. Eis um exemplo de [10] para exemplificar uma conversão congruente:

Tomemos por exemplo a seguinte expressão e sua conversão em escrita algébrica: "o conjunto de pontos cuja ordenada é superior a abscissa"- $y>x$. Prevê-se que para efetuar a conversão é suficiente uma correspondência término a término entre as unidades significantes respectivas. Neste caso, a conversão inversa permite voltar a encontrar a expressão inicial do registro de partida (p. 50).

Já a não congruência ocorre quando é necessário utilizar algum conhecimento prévio, o qual não está no registro de partida para chegar ao registro de chegada.

Seja agora a expressão: "o conjunto de pontos que têm uma abscissa positiva $-x>0$. Na escritura algébrica não existe uma unidade significante que corresponda a 'positivo'; então para suprir essa carência é necessário recorre $\mathrm{a}^{\prime}>0^{\prime}$, que é a combinação de duas unidades significantes. Aqui não há correspondência término a término entre as unidades significantes respectivas da expressão: é necessária uma reorganização da expressão dada no registro de partida para obter a expressão correspondente no registro de chegada [10] (p. 50).

Para [11], isso pode ser considerado um paradoxo cognitivo do pensamento matemático em que a compreensão dos objetos matemáticos pode não ser mais do que uma compreensão conceitual e o acesso aos objetos matemáticos passa necessariamente por representações semióticas.

Esse paradoxo pode constituir-se num grande círculo para a aprendizagem. Como os sujeitos em aprendizagem poderiam não confundir os objetos matemáticos com suas representações semióticas, se eles podem tratar apenas com as representações semióticas [11] (p. 268)? 
Nesse sentido, [11] sugere que a aprendizagem efetiva das propriedades de um objeto ocorre justamente na passagem de um registro para outro, pois as diferentes representações contêm peculiaridades distintas sobre um mesmo objeto.

O funcionamento cognitivo do pensamento humano evidência a existência de diferentes registros semióticos de representação, chamada "semiose a apreensão ou a produção de uma representação semiótica, e noesis a apreensão conceitual de um objeto, é preciso afirmar que a noesis é inseparável da semiose" [12] (p. 270).

Segundo [9], a atividade matemática de utilizar simultaneamente ao menos dois registros de representação ou trocar de registro de representação a todo o momento manifesta a criatividade do aluno. O número de representações mobilizadas no estudo de um objeto matemático influencia a possibilidade de entendimento desse objeto pelo aluno.

Nesse sentido, além da conversão, mais importante é a coordenação entre os registros, ou seja, enxergar nos diferentes registros o mesmo objeto matemático representado. Para Duval [12] (p. 270), a coordenação de muitos registros de representação semiótica aparece, fundamentalmente, para uma apreensão conceitual de objetos: é preciso que o objeto não seja confundido com suas representações e que seja reconhecido em cada uma de suas representações possíveis.

Nessa perspectiva, é significativo que no ambiente de ensino surjam diferentes registros para um mesmo objeto matemático e que seja necessário realizar a conversão e a coordenação entre esses registros. Enquanto a semiosis apresenta os vários registros de representação em relação a um conceito, a noesis busca a coordenação entre esses registros.

Portanto, o ensino de Matemática deve se pautar pelas diferentes formas de representações de um objeto matemático e pela possibilidade de trocar de representação sempre que necessário, pois o aluno somente poderá compreendê-lo melhor por meio da mobilização das representações.

\section{METODOLOGIA}

Esta proposta teve como objetivo analisar dados e registros produzidos por alunos que ainda estavam cursando o Ensino Médio, refletir e discutir as contribuições da Modelagem Matemática na aprendizagem dos estudantes participantes das atividades realizadas no âmbito do projeto ao qual este trabalho estava vinculado. Essas características fazem com que o trabalho a ser descrito aqui se aproxime da pesquisa de caráter qualitativo.

De acordo com [3] (p. 104), a realização de uma pesquisa qualitativa possibilita "[. . . ] a ideia do sujeito, possível de expor sensações e opiniões. O significado atribuído 
a essa concepção de pesquisa também engloba noções a respeito de percepções de diferenças e semelhanças de aspectos comparáveis de experiências".

$\mathrm{Na}$ abordagem qualitativa, a pesquisa tem o ambiente como fonte direta dos dados. Essa modalidade de pesquisa possibilita ao pesquisador manter contato direto com o ambiente e o objeto de estudo em questão, necessitando de um trabalho mais intensivo de campo, momento em que o investigador recolhe informações que lhe ajudarão a responder a suas indagações e que também podem surgir novos questionamentos.

Já [17] considera que na pesquisa qualitativa "há uma relação dinâmica entre o mundo real e o sujeito, isto é, um vínculo indissociável entre o mundo objetivo e a subjetividade do sujeito que não pode ser traduzido em números".

Os dados coletados nessas pesquisas são descritivos, retratando o maior número possível de elementos existentes na realidade estudada. Nessa perspectiva, [7] (p. 208) afirma que:

Os pesquisadores qualitativos geralmente coletam múltiplas formas de dados, tais como entrevistas, observações e documentos, em vez de confiarem em uma única fonte de dados. Depois os pesquisadores examinam todos os dados, extraem sentido deles e os organizam em categorias ou temas que cobrem todas as fontes de dados.

A sistematização e a organização da pesquisa estão diretamente relacionadas ao trabalho de campo, visando à análise dos dados sem se preocupar em comprovar hipóteses previamente estabelecidas, atentando-se mais ao processo do que ao produto.

Em última análise, o fato de caracterizar a natureza de nossa pesquisa como qualitativa não pressupõe uma negação dos dados quantitativos. O que determina uma metodologia quantitativa ou qualitativa é a maneira pela qual se pretende analisar o fenômeno e o enfoque adotado. Desse modo, [17] (p. 195) afirmam que:

[...] os investigadores qualitativos dispõem-se à recolha de dados quantitativos de forma crítica. Não é que os números por si sós não tenham valor. Em vez disso, o investigador qualitativo tende a variar o processo de compilação na sua cabeça perguntando-se o que é que os números dizem acerca das suposições das pessoas que os usam e os compilam. [. . .] Os investigadores qualitativos são inflexíveis em não tomar os dados quantitativos pelo seu valor facial.

Assim, o tipo de abordagem utilizada na pesquisa dependerá dos interesses do pesquisador, respeitando-se os limites do estudo proposto. Isso significa que o entendimento de diferentes tipos de estudo e suas classificações são fundamentais para a obtenção do sucesso na realização da pesquisa científica. 
A realização das atividades do projeto na escola envolveu os alunos e o professor de Matemática do $1 .^{\circ}$ ano do Ensino Médio, no turno matutino. Optou-se por esse ano escolar pois entende-se que função afim é um conteúdo programático da série escolhida. Participaram 30 alunos com idade entre 15 e 17 anos, dos quais mais da metade possui como ocupação apenas estudos.

Os alunos se organizaram em duplas, ficando à escolha deles a composição dos pares. Essas duplas foram identificadas por um código, por exemplo: a primeira dupla foi chamada de D1, a segunda de D2, a terceira de D3 e assim por diante.

Com o objetivo de contemplar a metodologia apresentada para a pesquisa, foram realizados 16 encontros com 50 minutos de duração cada. Normalmente, as aulas eram ministradas nos primeiros horários do turno matutino. Nesses encontros, foram trabalhados assuntos que compõem o conteúdo de função afim para a construção do modelo almejado.

O contato com a escola se deu por meio da figura do professor da turma, que é professor de Matemática na escola em que a pesquisa foi realizada e o terceiro autor deste artigo. Ele viabilizou a conversa com o corpo diretivo da instituição escolar, que culminou numa parceria que viabilizou o desenvolvimento da primeira etapa do projeto "Modelagem Matemática como ferramenta de ensino e aprendizagem", o qual nos possibilitou, por meio do Conselho Nacional de Pesquisa (CNPq), uma bolsa de iniciação científica à primeira autora desta obra. O primeiro encontro com a turma foi o momento de apresentação do projeto, expondo a forma de trabalho aos alunos participantes da pesquisa para a realização das tarefas de maneira satisfatória e organizada.

O tema para a Modelagem Matemática foi escolhido pela pesquisadora, compatibilizando-se com o conteúdo programático do ano escolar que os alunos estavam cursando.

Para expor o tema aos alunos foram colocadas as seguintes questões: Vocês conhecem uma conta de água? Quem já teve a curiosidade de analisar as informações e como os dados são processados em uma conta de água? Conhecem as tarifas que são cobradas na conta de água e como é calculado o valor total a pagar?

Para contribuir de forma teórica para o estudo realizado com as contas de água de cada aluno, partiu-se de discussões da leitura da conta da água, as quais levassem à compreensão dos alunos as tarifas cobradas.

Desse instrumento (modelo de conta d'água) foram exploradas todas as informações, conforme apresentadas no Quadro 1. 
Quadro 1: Passos para leitura da conta de água

\begin{tabular}{l} 
O que é necessário saber sobre a conta de água? \\
\hline A Conta/Fatura de Fornecimento de Água, da SAE (Superintendência de Água e Esgotos), \\
contém alguns campos importantes, aos quais você deve estar atento. \\
Os principais estão assinalados no exemplo de conta ao lado. Confira abaixo a descrição de \\
cada um: \\
1. Serviços: descrição dos serviços que estão sendo cobrados na fatura, como: tarifa de \\
água, tarifa de esgoto, conservação de hidrômetro, multa e juros de mora. \\
2. Dados da leitura e consumo: contêm: o mês e ano de emissão da conta, a média de \\
consumo dos últimos 6 meses, as leituras anterior e atual, os dias de consumo faturados na \\
conta e o consumo mensal em $\mathrm{m}^{3}$. \\
3. Consumo real: série histórica de consumo dos últimos 6 meses.
\end{tabular}

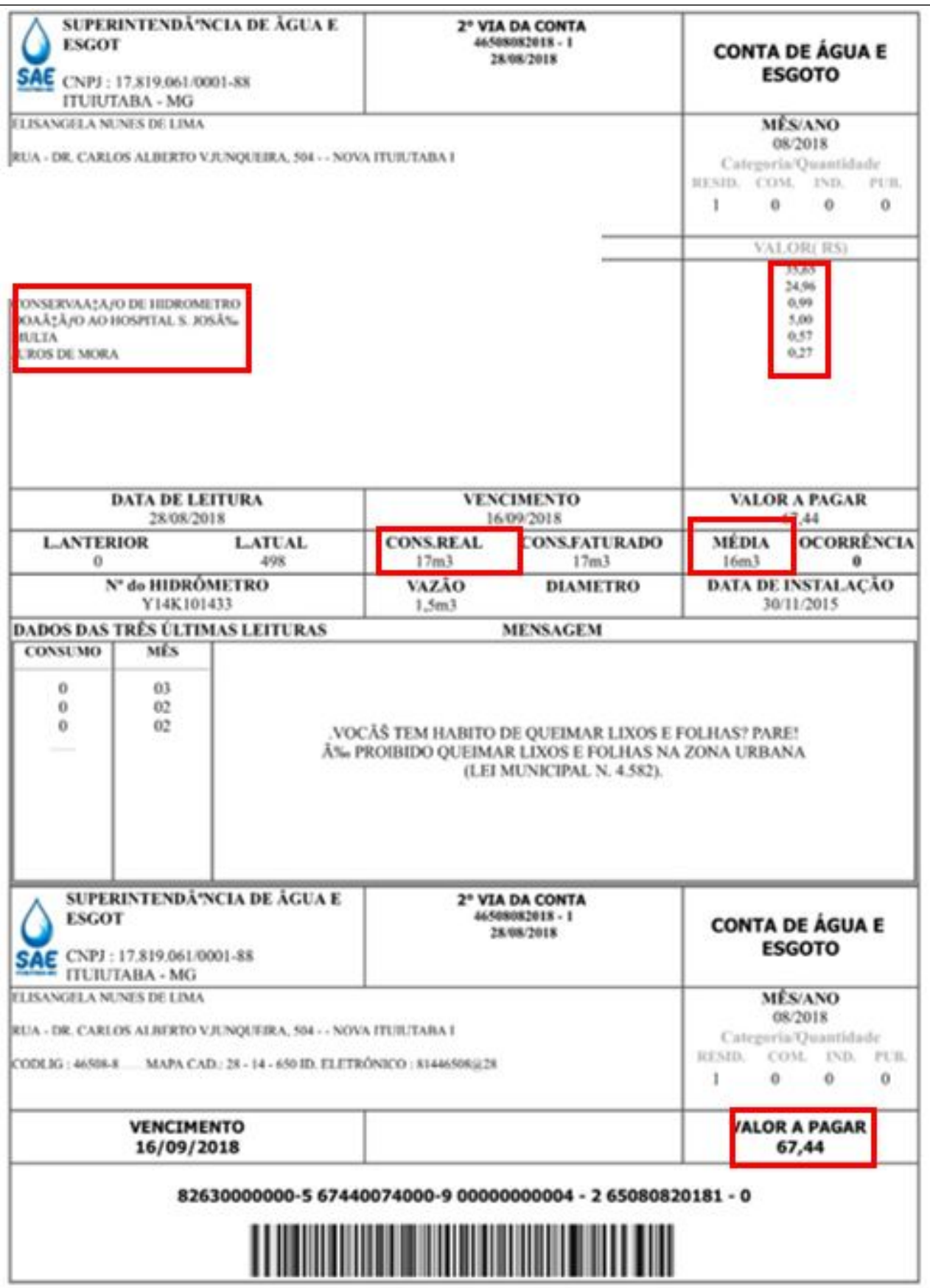

Fonte: Elaborada pelos autores 
A partir da conta de água dos estudantes foram elaboradas sete tarefas realizadas e discutidas com a turma ao longo de 16 encontros. Os resultados dessas tarefas serão apresentados na seção seguinte.

\section{ANÁLISE E DISCUSSÃO DOS DADOS}

Inicialmente, para que se tenha uma ideia do desempenho dos estudantes ao longo do processo nos 16 encontros, foi realizada uma análise quantitativa, no sentido de obter um panorama geral desse desempenho. Tal análise é possível ser observada na Tabela 1 a seguir.

Tabela 1: Passos para leitura da conta de água

\begin{tabular}{|c|c|c|c|c|c|c|c|c|c|c|}
\hline \multirow[t]{2}{*}{ Tarefas } & \multicolumn{2}{|c|}{ Correto } & \multicolumn{2}{|c|}{$\begin{array}{c}\text { Parcialmente } \\
\text { correto }\end{array}$} & \multicolumn{2}{|c|}{ Incorreto } & \multicolumn{2}{|c|}{$\begin{array}{c}\text { Em } \\
\text { branco }\end{array}$} & \multicolumn{2}{|c|}{ Total } \\
\hline & N. ${ }^{\circ}$ & $\%$ & N. ${ }^{0}$ & $\%$ & N. ${ }^{\circ}$ & $\%$ & N. ${ }^{\circ}$ & $\%$ & N. ${ }^{\circ}$ & $\%$ \\
\hline Tarefa 01 & 29 & 96,7 & 0 & 0 & 0 & 0 & 1 & 3,3 & 30 & 100,0 \\
\hline Tarefa 02 & 20 & 66,7 & 10 & 33,3 & 0 & 0 & 0 & 0 & 30 & 100,0 \\
\hline Tarefa 03 & 26 & 86,6 & 2 & 6,7 & 0 & 0 & 2 & 6,7 & 30 & 100,0 \\
\hline Tarefa 04 & 22 & 73,4 & 7 & 23,3 & 0 & 0 & 1 & 3,3 & 30 & 100,0 \\
\hline Tarefa 05 & 23 & 76,7 & 6 & 20 & 0 & 0 & 1 & 3,3 & 30 & 100,0 \\
\hline Tarefa 06 & 9 & 30 & 19 & 63,3 & 2 & 6,7 & 0 & 0 & 30 & 100,0 \\
\hline Tarefa 07 & 5 & 16,7 & 4 & 13,3 & 19 & 63,3 & 2 & 6,7 & 30 & 100,0 \\
\hline Total & 134 & & 48 & & 21 & & 7 & & 210 & \\
\hline
\end{tabular}

Fonte: Elaborada pelos autores

Os dados da tabela indicam que, dentre as 210 tarefas desenvolvidas pelos alunos, 134 foram realizadas corretamente, 48 foram consideradas parcialmente corretas, 21 foram apresentadas incorretamente e 7 tarefas não apresentavam resolução.

A tarefa 1 foi a que obteve um maior índice de acertos, quase 29 alunos, ou seja, 96\%. Isso ocorreu pois se tratava de uma atividade cujo custo cognitivo, segundo [12], não é tão grande porque eles apenas precisavam preencher uma tabela e para isso seria necessário apenas um cálculo de porcentagem que poderia ser feito por meio de uma operação de multiplicação.

Em contrapartida, a tarefa 7 foi a que alcançou um menor número de acertos, a qual exigia um maior custo cognitivo cujos dados não estavam explícitos para construção do gráfico. O aluno tinha que fazer uma interpretação da conta de água dele e da conta do colega e construir algo que para eles ainda era novo, o gráfico da função afim. Isso demanda, de acordo com [12], um custo cognitivo maior no sentido de que o estudante precisava realizar uma conversão dos dados que estão na língua materna do consumo para uma representação gráfica da função afim. Após uma visão geral do desempenho 
dos participantes, por meio de uma breve análise quantitativa, passou-se a examinar as estratégias utilizadas por eles na realização das tarefas.

Iniciou-se pela tarefa 01, a qual, como dito anteriormente, é uma tarefa cujo registro de partida é o tabular, que consistia em completar a tabela em que o estudante deveria fazer um tratamento, pois a resposta permaneceu em forma de tabela para realização de um tratamento.

Apesar de todos os alunos terem realizado corretamente essa tarefa, não foi imediato o preenchimento da tabela, pois surgiram dificuldades de efetuar os cálculos de porcentagem. Nesse momento, o professor regente e a pesquisadora fizeram algumas intervenções para ensinar procedimentos de cálculo de porcentagem.

Para melhor compreender o procedimento, foi utilizado um exemplo com a tarifa mínima da primeira faixa de consumo: tem-se que $70 \%=70 / 100=0,70$; então, 0,70 vezes 17,59 tem-se 12,31 . Isso pode ser verificado em destaque na Figura 1 , na tarefa realizada pelo aluno que recebeu o código A10.

Isso vai ao encontro do que salientam [5], quando afirmam que, ao perceber que o ferramental matemático dos alunos não é suficiente para prosseguir com o processo de modelagem, o professor deve pausar o processo e aprofundar o conteúdo que servirá como ferramenta no processo de modelagem.

Figura 1: Resolução apresentada por A10

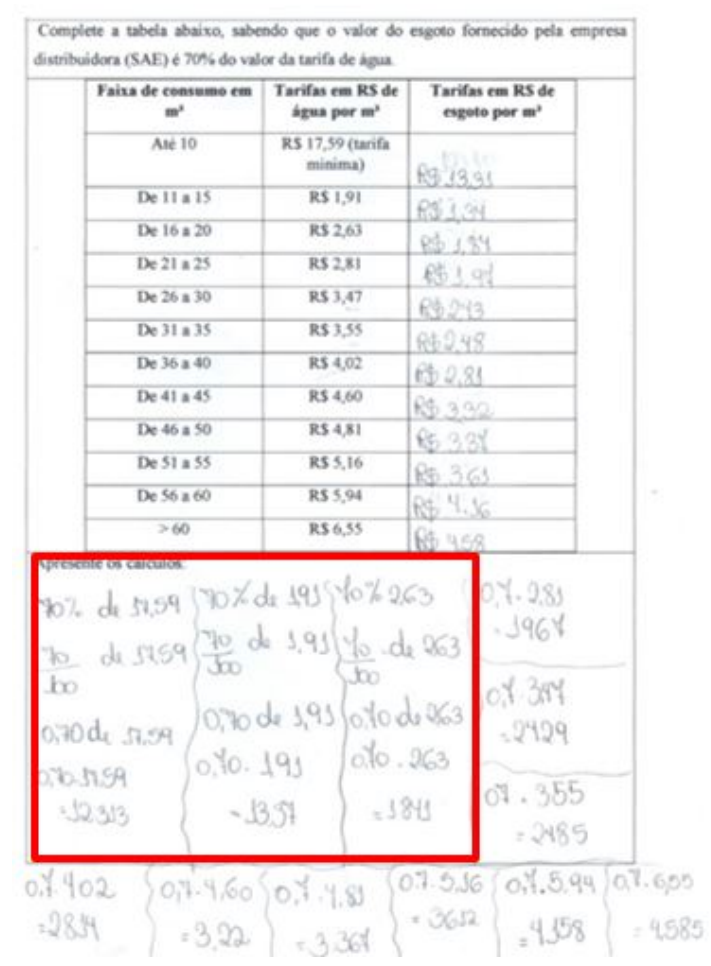

Fonte: Elaborada pelos autores

Outros alunos aparentavam dominar o conceito de porcentagem e, sabendo que 
70\% correspondia a 0,70, apenas realizavam cálculo de multiplicação, como foi verificado na tarefa do A5 apresentado na Figura 2.

Figura 2: Resolução apresentada por A5

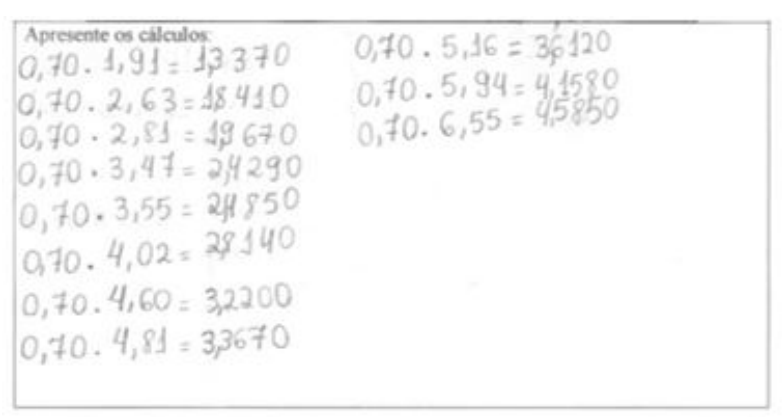

Fonte: Elaborada pelos autores

Já na tarefa 2, que também consiste no registro tabular, exigia-se uma conversão do registro simbólico numérico para registro algébrico. Essa conversão, segundo [11], é considerada não congruente, pois não é possível, a partir do registro de partida, visualizar os registros de chegada, ou seja, as unidades de sentido do registro de partida não transparecem na representação do registro de chegada.

Nessa tarefa, grande parte dos alunos encontrou dificuldades e, em diversos momentos, foram necessárias algumas intervenções, pois os alunos não tinham o domínio da conversão que seria realizada.

Apesar das muitas dificuldades com essa tarefa, a maioria dos alunos conseguiu chegar à solução correta. Nesse sentido, as respostas corretas também devem ser investigadas pelo professor, pois, assim, ele pode ter um parâmetro das estratégias utilizadas pelos estudantes e identificar obstáculos que podem ser prejudiciais futuramente, ou, ainda, reconhecer diferentes formas de raciocínio dos estudantes. Assim, [9] enfatiza que, se quisermos saber como um sujeito faz Matemática, as conversões realizadas por ele devem ser observadas, pois nelas estão explícitas as maneiras como o indivíduo pensa e faz uso das ferramentas matemáticas.

Para essa discussão, trouxemos a seguir a atividade realizada por A18 ilustrada na Figura 3.

Ao analisar a produção escrita, é importante que o professor busque também todas as formas de resoluções parcialmente corretas e incorretas apresentadas pelos alunos. A atividade retratada na Figura 3, realizada por A18, consiste em uma conversão não congruente, pois os elementos do registro de partida que estão na representação simbólico-numérica foram convertidos para a representação algébrica, que corresponde ao modelo que determina o valor a ser pago pela água em cada faixa de consumo. É possível perceber que as unidades semânticas da representação do 
Figura 3: Resolução apresentada por A18
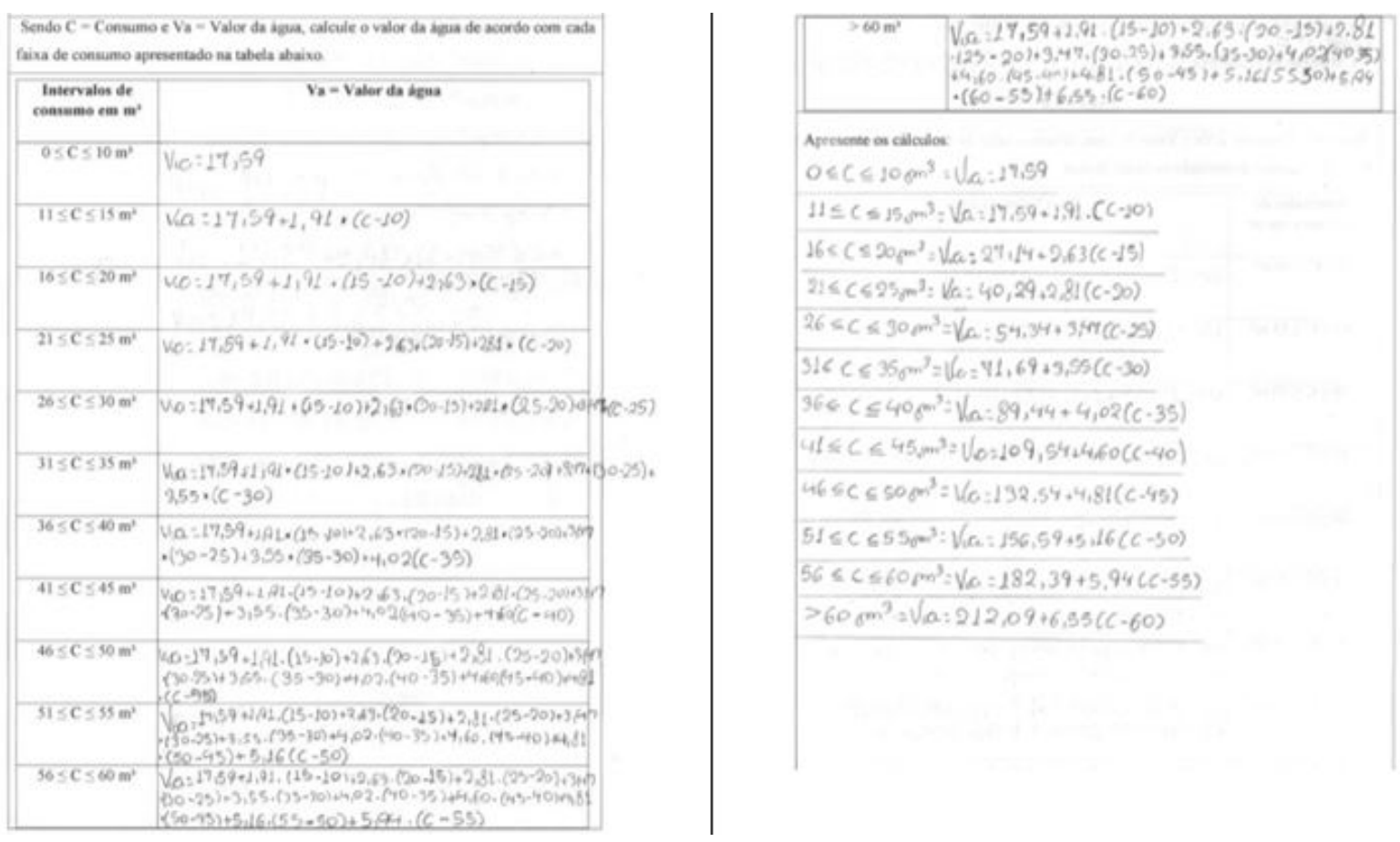

Fonte: Elaborada pelos autores

registro de partida não transparecem totalmente no registro de chegada. Isso é evidência clara do fenômeno de não congruência. Contudo, segundo [9], apesar do custo cognitivo exigido do indivíduo para executar uma tarefa que apresenta esse fenômeno e do distanciamento existente entre as duas representações (partida e chegada), o professor não deve evitar esse tipo de fenômeno, pois é ele que trará ao aprendiz consistência na argumentação matemática e apropriação do conceito.

Na tarefa 3, em que os alunos deveriam efetuar cálculos para determinar o valor a pagar pelo esgoto em cada faixa de consumo, também demandava-se uma conversão quando a representação simbólico-numérica era convertida para a representação algébrica, com análise análoga à tarefa 2.

Apesar de essa atividade apresentar o fenômeno de não congruência semântica na conversão, por trazer dificuldades de reconhecimento do conteúdo ao transformar um registro por outro, a maioria dos alunos conseguiu chegar à solução sem grandes obstáculos, o que pode ser percebido na Figura 4, tarefa executada por A4. Talvez isso se deve ao fato de que para encontrar a solução da tarefa 3 era necessário realizar o mesmo procedimento da tarefa 2, porém utilizando tarifas referentes ao esgoto.

Diferente das tarefas 2 e 3, não foi identificada a mudança de registros simbóliconuméricos para o registro algébrico na tarefa 4. Isso acontece porque essa tarefa se resumiu apenas à soma de registros algébricos representados pelas expressões en- 
Figura 4: Resolução apresentada por A4

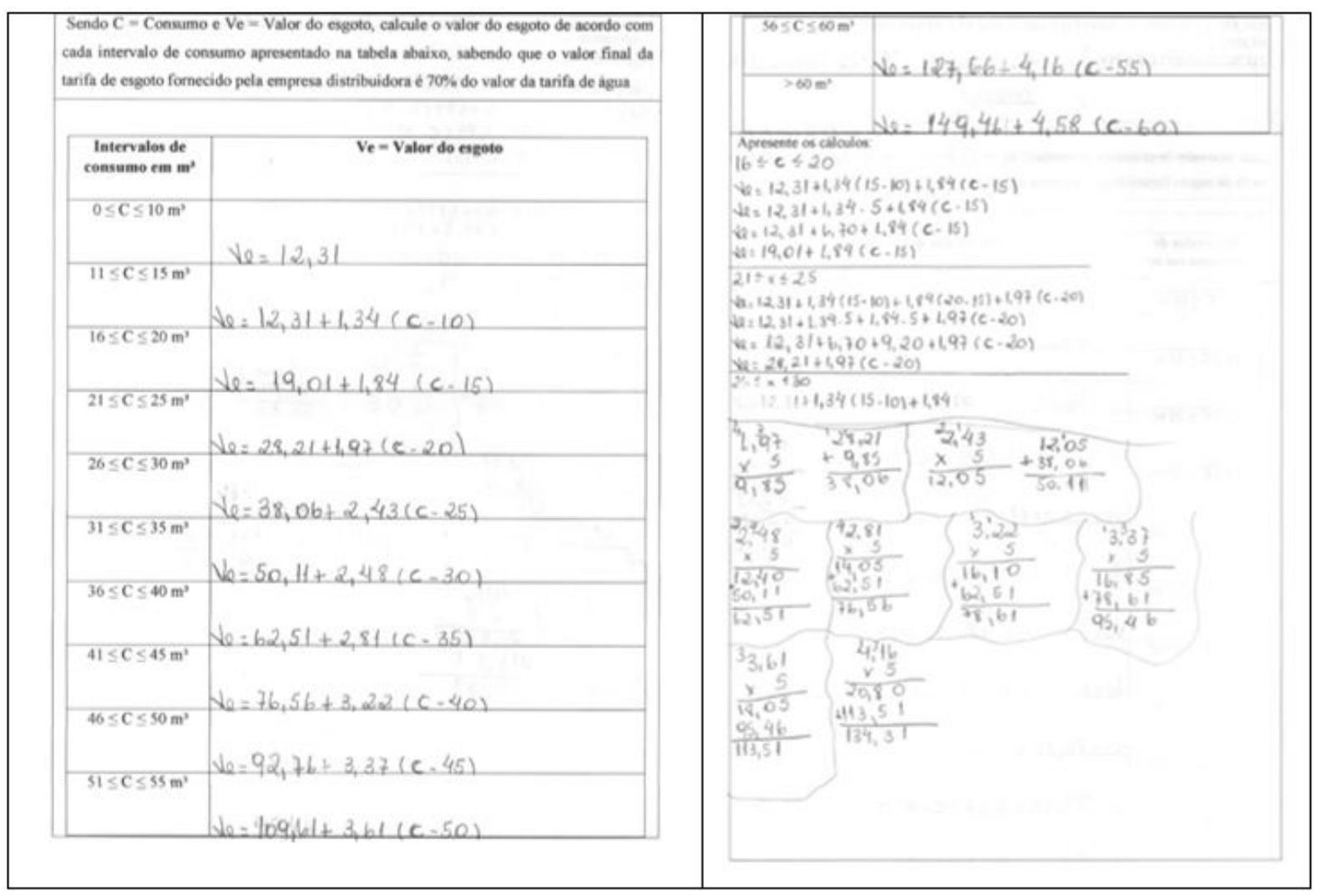

Fonte: Elaborada pelos autores

contradas para os valores da água e esgoto. Na Figura 5 a seguir é possível observar os tratamentos algébricos realizados corretamente por A14, que se resume em operar com polinômios.

Na tarefa 5, o aluno usou a representação algébrica função afim da forma $f(c)=$ $a c+b$, associando $a$ (coeficiente angular) e $b$ (coeficiente linear) ao custo variável e fixo da função respectivamente e custo total $f(c)$. Para representar o valor total da conta de água, que depende do consumo em $\mathrm{m}^{3}$, este utiliza a variável $c$. A generalização de padrões oportuniza uma nova forma de comunicação, quando tratamos da linguagem algébrica, propiciando ao estudante analisar a situação proposta e expressá-la numa linguagem mais elaborada.

A partir da substituição do valor de $c$ (presente na conta de água), na expressão algébrica, os alunos encontraram o custo total a ser pago. Assim, os alunos puderam confirmar o valor de $f(c)$, o que seria, segundo [9], uma forma de tratamento, uma vez que as transformações realizadas por eles foram internas ao mesmo registro algébrico. 
Figura 5: Resolução apresentada por A14

Chamaremos de valor total $(\mathrm{V} t)$, no entanto, na fatura de serviços não é dado um nome especificamente para este valor porque existem outras tarifas a serem cobradas como a conservação de hidrômetro, multa de atraso e juros de moradia, somando tudo, no final e dado o nome de valor total. Para calcular o valor total $(\mathrm{Vt})$, faremos: $\mathrm{Va}+\mathrm{Ve}$, para cada faixa de consumo

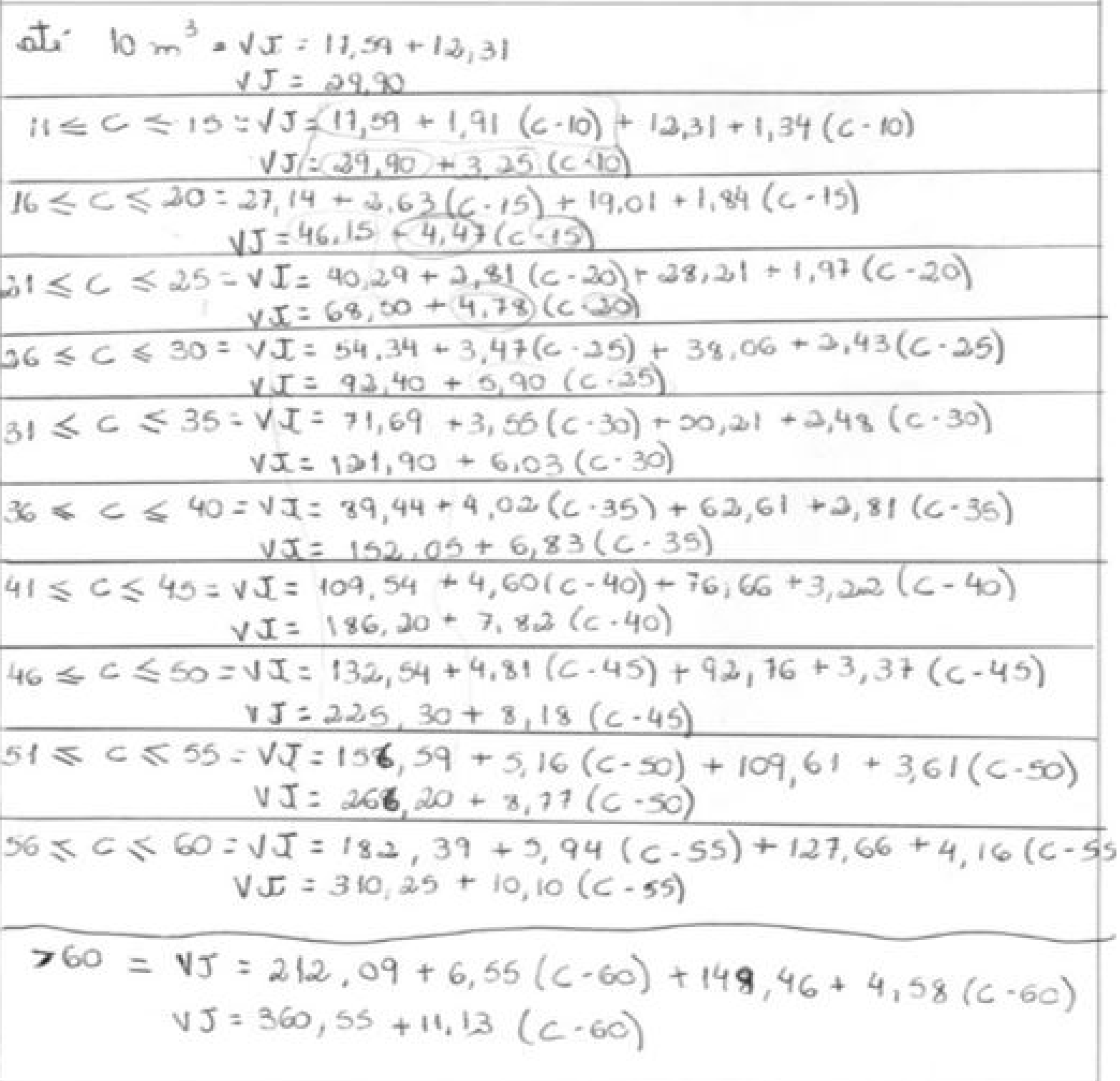

Fonte: Elaborada pelos autores

$\mathrm{Na}$ Figura 6 a seguir, o estudante A7 apresenta para cada faixa de consumo a função de generalização da situação dada, a qual permite calcular o valor total da conta de água para qualquer consumo real em $\mathrm{m}^{3}$. 
Figura 6: Resolução apresentada por A14

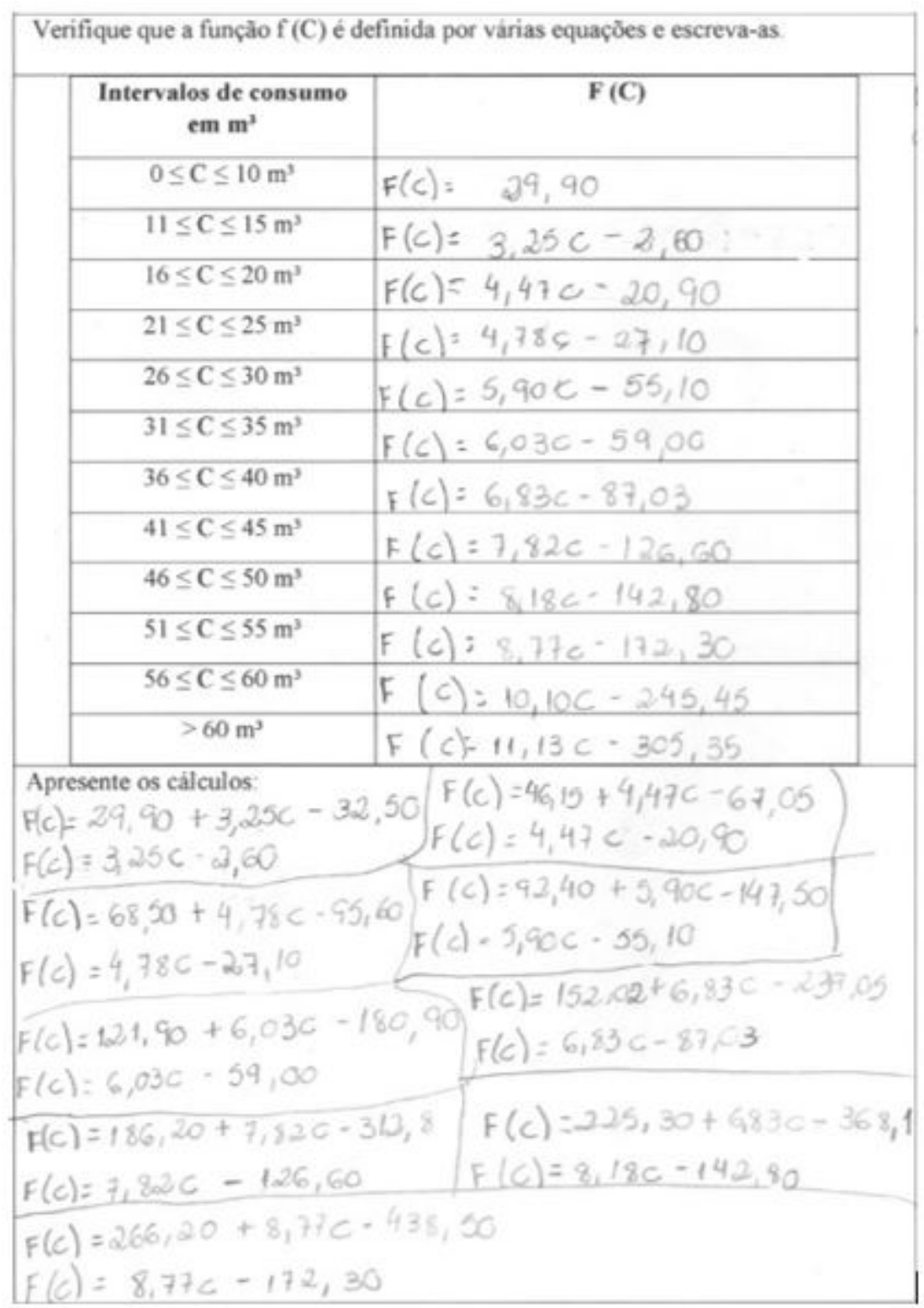

Fonte: Elaborada pelos autores

Após executar essa atividade, em que os alunos puderam verificar a função $\mathrm{F}$ em cada um dos intervalos, o que se constituiu o que [5] chama de momento de validação do modelo matemático, foi apresentada a seguinte definição: uma função $f: \mathbb{R} \rightarrow \mathbb{R}$ chama-se afim se existem constantes $a, b \in \mathbb{R}$ tais que $f(x)=a x+b$ para todo $x \in \mathbb{R}$.

A tarefa 6 consistia em representar no plano cartesiano as equações da tarefa 5 , que mostra a relação do consumo d'água em metros cúbicos e o valor a ser pago à empresa. A Figura 7 a seguir retrata os gráficos de três alunos, dividida em três imagens. A imagem A é referente ao aluno A3, classificada como resposta correta; a imagem $B$ é referente ao aluno $A 1$, considerada como resposta parcialmente correta; e a imagem $C$ é referente ao aluno A6, categorizada como resposta incorreta. 
Figura 7: Exemplos de respostas apresentadas pelos alunos

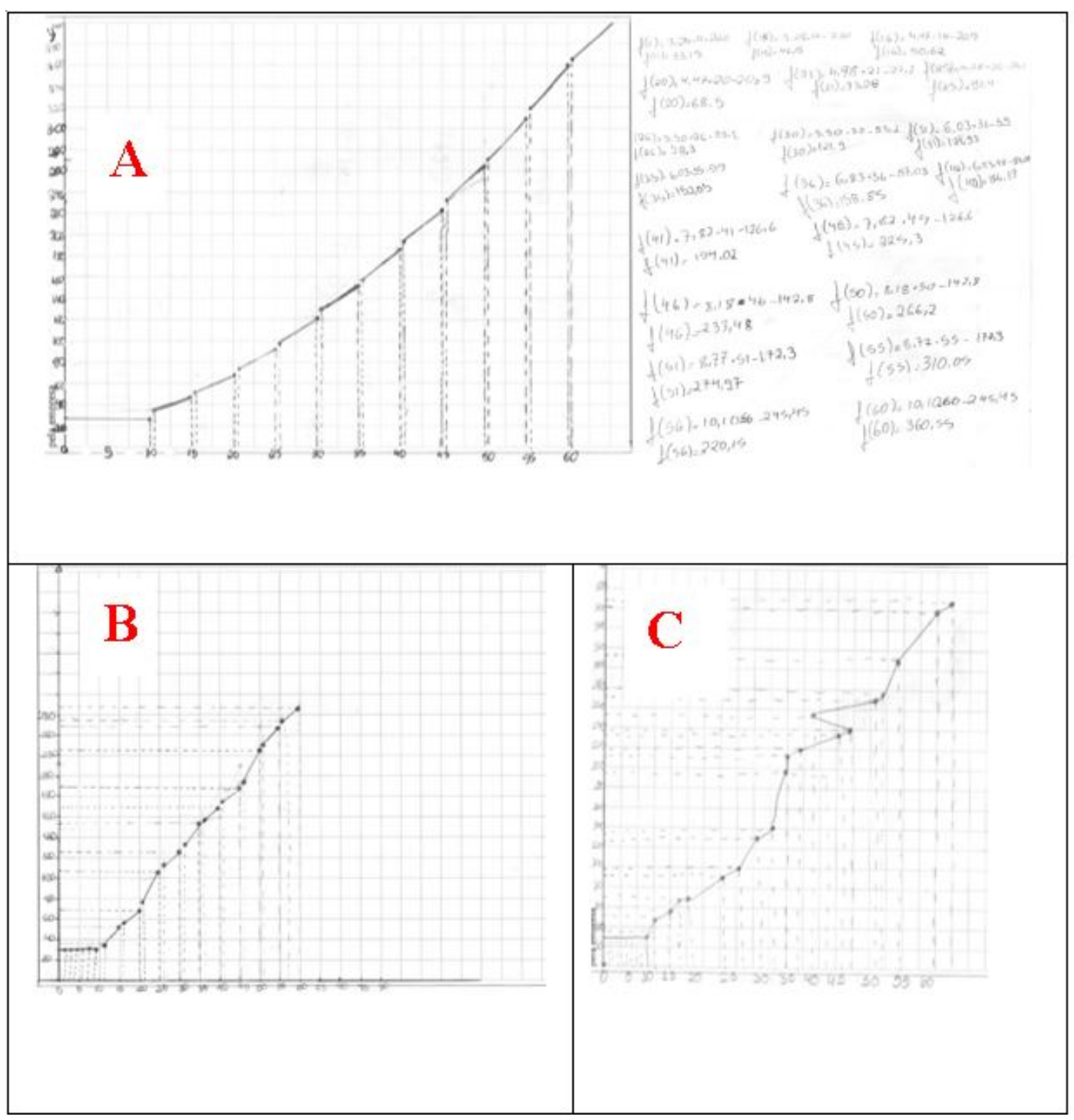

Fonte: Elaborada pelos autores

Analisando a imagem A (gráfico e cálculos algébricos), percebeu-se que o aluno representou as funções de custo em função da faixa de consumo corretamente, ao considerar os pontos extremos de cada intervalo, observado nos cálculos do lado superior direito da Figura 7. Portanto, o aluno traçou cada segmento de maneira que $C$ variasse entre esse intervalo fechado. O gráfico esboçado por A1 foi definido como parcialmente correto associado ao código, pois a função considerada da faixa de consumo para gastos acima de $60 \mathrm{~m}^{3}$ a ser representada graficamente está incorreta, o que levou ao aluno a representar em intervalo fechado. Nesse caso, a empresa cobra o valor máximo de $\mathrm{R} \$ 362,45$ por qualquer gasto igual ou maior a 60 mil litros de água mensais.

Já na imagem C o aluno esboçou o gráfico das funções custo equivocadamente, erro associado. O erro mais visível é o do traço "retroceder", característica que não 
faz parte das funções em sua representação gráfica. Além disso, como o intervalo das faixas de consumo é fechado, o gráfico que representa todas as funções de custo não é contínuo em alguns pontos entre os intervalos. Assim, foi identificado também esse erro na tarefa realizada por A6.

Somente $30 \%$ dos alunos acertaram essa tarefa totalmente. É possível associar esse baixo índice de acertos ao fato de que essa atividade exigia que os alunos realizassem uma conversão entre dois registros diferentes. A mudança de registros discursivos para registros não discursivos, segundo [11], é não congruente, pois não é possível, a partir do registro algébrico, visualizar os registros gráficos. Como essa conversão exige um custo cognitivo maior devido à quantidade de tratamentos a serem feitos antes da conversão, isso refletiu na quantidade de alunos que erraram ou acertaram.

A tarefa 7 consistia em representar no mesmo plano cartesiano os gráficos referentes aos consumos presentes nas contas de dois alunos distintos. Como na tarefa anterior, nela também foi identificado o fenômeno da não congruência entre os registros de partida (algébrico) e de chegada (gráfico). Como podemos observar na Figura 8 a seguir, nas imagens $D$ e $E$ os alunos não conseguiram realizar a mudança de registros corretamente.

Figura 8: Exemplos de respostas apresentadas pelos alunos

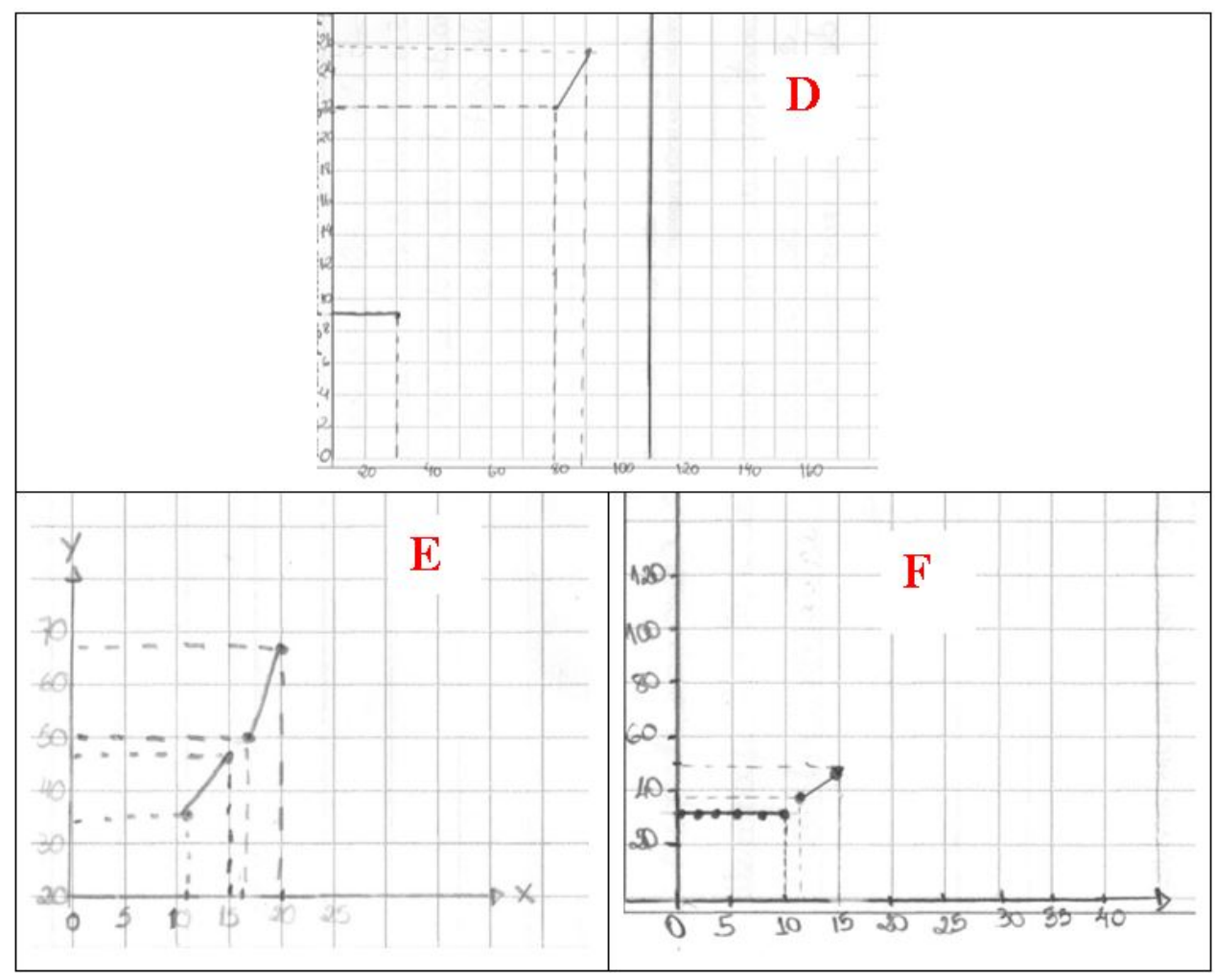

Fonte: Elaborada pelos autores 
O caráter dessa tarefa é de validação do modelo matemático, de acordo com [5]. Essa sequência de atividades compreendida da tarefa 1 a 7 é considerada uma Modelagem Matemática, na visão de [5], uma vez que puderam ser trabalhadas as seguintes fases: (a) Interação: antes de começar as tarefas, houve uma interação entre a pesquisadora e os alunos, que partiu de discussões sobre o conhecimento dos alunos acerca das contas de água de suas residências; (b) Matematização: essa etapa foi empregada nas tarefas 1, 2, 3, 4 e 5 com o objetivo de traduzir a situação real de tarifas das contas de água para uma linguagem matemática, predominantemente em registros algébricos: função afim; c) Modelo Matemático: ainda nas tarefas 5, 6 e 7 as funções puderam ser verificadas, interpretadas e validadas como modelo matemático. Essas funções foram constatadas em dois tipos de registros (algébrico e gráfico), em que no registro cartesiano puderam ser feitas atividades de interpretações e ainda puderam validar as funções calculando suas próprias contas de água e d seu parceiro da dupla. Por fim, esta proposta proporcionou momentos nos quais os participantes puderam apropriar-se da Matemática como ferramenta para compreender os fenômenos presentes na sociedade.

\section{CONSIDERAÇÕES FINAIS}

Este trabalho é resultado de um estudo pautado pelas implicações do uso da Modelagem Matemática como ferramenta de ensino.

Ao empregar a metodologia Modelagem Matemática, aliada ao tema conta de água, foi possível estabelecer uma relação entre teoria e prática. Por meio das atividades em grupo, discussões e respostas apresentadas pelos alunos, evidenciou-se que, apesar dos contratempos e das dificuldades sentidas pelos estudantes, pôde-se evidenciar uma aprendizagem que trouxe significado para o conteúdo trabalhado.

Durante a pesquisa, os alunos demonstraram interesse e satisfação em realizar as atividades propostas, uma vez que a metodologia adotada favoreceu a compreensão deles com relação aos cálculos, à interpretação e à construção dos gráficos.

Ao desenvolver as atividades de Modelagem Matemática, estabeleceu-se o uso de diferentes registros de representação, bem como a execução de sucessivas conversões entre eles.

As conversões efetuadas foram muito importantes para que pudéssemos perceber a variedade de representações de um objeto. Nesse sentido, não poderíamos compreender nosso objeto de estudo, função afim, sem antes ter clareza de que ele poderia ser representado de várias maneiras.

A teoria dos Registros nos ajudou a entender que a peculiaridade da Matemática está na mobilização simultânea de pelo menos dois registros de representação ao 
mesmo tempo, o que dificultaria a compreensão do objeto matemático, caso não acontecesse essa condição.

Nesse sentido, a teoria nos deu suporte também para explicar por que não acontece de forma natural a conversão de uma função escrita na forma algébrica para a representação gráfica, o que ocorre em razão do fator da não congruência, ao impedir o estudante de perceber o objeto em várias representações.

A utilização da Modelagem Matemática para relacionar os cálculos matemáticos ao cotidiano dos alunos proporcionou algumas reflexões que possibilitaram aos alunos constatar alguns resultados obtidos e questioná-los.

Por meio dos resultados alcançados, os alunos estabeleceram relações entre o consumo real e o valor a ser pago na conta de água, concluindo que são cobradas altas tarifas nas diversas faixas de consumo e, para o consumo de até $10 \mathrm{~m}^{3}$, é estipulado um valor fixo a pagar, o que não é coerente com uma pessoa que atingiu um consumo menor no período de um mês. Essas discussões estão pautadas pelas vertentes da Educação Matemática Crítica, que postula que a Matemática é uma ferramenta que promove a compreensão de mundo e possibilita a seu usuário o desenvolvimento do senso crítico e do poder de argumentação.

Os resultados apresentados advindos de observações das atividades de Modelagem Matemática viabilizaram indícios de construção do conhecimento matemático e reflexivo, promovendo o exercício da cidadania.

Diante do exposto, espera-se que este estudo contribua com a área de ensino de Matemática, no que se refere ao tema função afim, e seja relevante para pesquisas em Educação Matemática.

\section{REFERÊNCIAS}

[1] J. C. Barbosa, Modelagem na educação matemática: uma perspectiva, in: Encontro Paranaense de Modelagem em Educação Matemática, 1, 2004b, Londrina, Anais, UEL, Londrina, 2004, 1 CD-ROM.

[2] R. C. Bassanezi, Ensino-aprendizagem com modelagem matemática: uma nova estratégia, Contexto, São Paulo, 2002.

[3] M. A. V. Bicudo, Pesquisa Qualitativa e pesquisa qualitativa segundo a abordagem fenomenológica, in: M. C. Borba, J. L. Araujo, Pesquisa qualitativa em educação matemática, Autêntica, Belo Horizonte, 2004, pp. 99-112.

[4] M. S. Biembengut, Modelagem matemática \& implicações no ensino-aprendizagem de matemática, Furb, Blumenau, 1999.

[5] M. S. Biembengut, N. Hein, Modelagem matemática no ensino, 5. ed., Contexto, São Paulo, 2009.

[6] C. E. P. Brumano, A modelagem matemática como metodologia para o estudo de análise combinatória, 2014. 
[7] J. W. Creswell, Projeto de pesquisa: métodos qualitativo, quantitativo e misto, Trad. M. Lopes, Artmed, Porto Alegre, 2010.

[8] U. D'Ambrosio, Da realidade à ação: reflexões sobre educação e matemática, Ed. Universidade Estadual de Campinas, Campinas, 1986.

[9] R. Duval, Registros de representações semióticas e funcionamento cognitivo da compreensão em matemática, in: S. D. A. Machado, Aprendizagem em matemática: registros de representação semiótica, Papirus, Campinas, 2003, pp. 11-33.

[10] R. Duval, Semiosis y pensamiento humano: registros semióticos y aprendizajes intelectuales, Trad. M. V. Reestrepo, Peter Lang, Universidade Del Valle, 2004.

[11] R. Duval, Diferenças semânticas e coerência matemática: introdução aos problemas de congruência, Trad. M. T. Moretti, Revemat: Revista Eletrônica de Educação Matemática, 7 (2012) 1, 97-117.

[12] R. Duval, Registros de representação semiótica e funcionamento cognitivo do pensamento, Trad. M. T. Moretti, Revemat: Revista Eletrônica de Educação Matemática, 7 (2012) 2, 266-297.

[13] O. Fachin, Fundamentos da metodologia, Saraiva, São Paulo, 2005.

[14] P. Freire, Pedagogia da autonomia: saberes necessários a prática educativa, 30. ed., Paz e Terra, São Paulo, 2004.

[15] G. Granger, A razão, 2. ed., Difusão Europeia do Livro, São Paulo, 1969.

[16] Brasil, Parâmetros Curriculares Nacionais - Terceiro e Quarto Ciclos do Ensino Fundamental Matemática, Ministério da Educação e do Desporto - Secretaria de Educação Fundamental, Brasília, 1998.

[17] C. C. Prodanov, E. C. Freitas, Metodologia do trabalho científico: métodos e técnicas da pesquisa e do trabalho acadêmico, 2. ed., Feevale, Novo Hamburgo, 2013.

\section{BREVE BIOGRAFIA}

Cássia Silva Costa (D) https://orcid.org/0000-0001-7152-8193

Licenciada em Matemática pela Universidade Federal de Uberlândia, Campus Pontal; ex-bolsista nos programas PIBID e Residência Pedagógica.

\section{Rogério Fernando Pires (D) https://orcid.org/0000-0001-5310-1997}

Doutor em Educação Matemática pela Pontifícia Universidade Católica de São Paulo (PUC-SP). Professor Adjunto do Instituto de Ciências Exatas e Naturais do Pontal (ICENP) da Universidade Federal de Uberlândia (Campus Ituiutaba); professor colaborador do Programa de PósGraduação em Ensino de Ciências Exatas (PPGECE) da UFSCar.

Carlos Eduardo Petronilho Boiago (D) https://orcid.org/

Doutorando em Educação, pelo Programa de Pós-graduação em Educação, da Faculdade de Educação da Universidade Federal de Uberlândia (UFU). Atualmente é professor no Ensino Médio da rede estadual de ensino de Minas Gerais e na Faculdade Mais de Ituiutaba-MG, atuando nas disciplinas Geometria Analítica, Estatística, Álgebra Linear e Cálculo. 